\title{
Knowledge and awareness of emergency contraception methods in rural and urban areas of Haryana, India
}

\author{
Sukhbir Pal Kaur, Susmita Sharma*, Gagan Lata
}

Department of Obstetrics and Gynecology, Adesh Medical College and Hospital, Mohri, Shahbad, Haryana, India

Received: 24 September 2019

Accepted: 31 October 2019

\section{*Correspondence:}

Dr. Susmita Sharma,

E-mail: sushmitasharma28@gmail.com

Copyright: (C) the author(s), publisher and licensee Medip Academy. This is an open-access article distributed under the terms of the Creative Commons Attribution Non-Commercial License, which permits unrestricted non-commercial use, distribution, and reproduction in any medium, provided the original work is properly cited.

\begin{abstract}
Background: Emergency contraception (EC) is usage of contraceptive method after an unprotected sexual intercourse. It provides a window of opportunity for females for prevention of an unplanned pregnancy. In India, emergency contraceptive usage continues to be very poor. Thus, this study was planned to analyse the knowledge, awareness, and practices of married women in Haryana towards EC methods.

Methods: This observational study was undertaken in a single centre on a section of rural and urban population in Haryana. A total of 500 women of reproductive age group were included in the study. A series of questions were asked in a face to face interview from a pre-structured questionnaire in a non-formal yet confidential environment. The data were collected, analysed, and compared with data available in literature.

Results: In our study, more than 50\% women had never heard of EC. Of those who were aware, majority $(95.83 \%)$ knew about EC pills. IUD as EC was known to a very few women (2.08\%). Television was the most common source of information followed by family and friends. The most common source of procurement of EC pills was from chemist shops (83.3\%). Very few women (4.1\%), knew the correct time for taking the EC pills.

Conclusions: Our study affirms a poor knowledge about use of emergency contraception among women in Haryana. Imparting knowledge through television, social media and incorporating and highlighting EC use in sex education programs can greatly help to increase the awareness and knowledge of correct EC use.
\end{abstract}

Keywords: Awareness, Emergency contraception, Knowledge, Perception

\section{INTRODUCTION}

Emergency contraception is usage of contraceptive method after an unprotected sexual intercourse. It provides a window of opportunity for females for prevention of an unplanned pregnancy. Emergency contraception (EC) is a safe and effective method. In India, even after contraceptive techniques being freely available, contraceptive coverage and usage continues to be very poor. More so in the rural population where contraceptive awareness and usage is still very poorly accepted. Even when pregnancy is not planned, exposure to unprotected sex may take place, which necessitates the use of emergency contraception. Emergency contraception may also be needed in case of contraceptive usage failure like condom rupture, condom slippage, delay in taking injectable contraceptive or missing pills more than two days and in cases of sexual assault. Emergency contraception thus can prevent a large number of unwanted pregnancies resulting from unplanned sexual activity or failure of regular contraception. It thus indirectly reduces the maternal mortality and morbidity due to unsafe abortions. In India, ECP was introduced in 2002 by the Ministry of Health 
and Family Welfare (MoHFW) and was made an over the counter (OTC) drug in 2005. Later in a survey it was revealed that less than one-third women were aware of ECP and less than one percent had ever used it. ${ }^{1} \mathrm{~A}$ detailed data from 8 states covered in the Annual Health Survey showed a very low (less than 0.2 percent) use of ECP. ${ }^{2}$ With this background, a study was thus planned with an aim to identify the knowledge and awareness of emergency contraception in a population of Haryana. Apart from assessing the knowledge of its usage, the profiles of EC users, causes of lack of knowledge, myths associated with EC, fear of using such a contraceptive method and its availability details were also analysed.

\section{METHODS}

This observational study was undertaken in a single centre on a section of rural and urban population in Haryana over a period of 3 months from June 2019August 2019. A total of 500 women of reproductive age group (15-45 years of age) were included in the study, and women outside this age range were excluded from the study. Also, women unwilling to participate were excluded from the study. Participants were asked a series of questions in a face to face interview from a prestructured questionnaire in local language and keeping in mind the social taboos attached to this topic, a local social worker was trained by the investigating team to ask questions in a non-formal yet confidential environment.

The questionnaire consisted of two parts; first part was demographic details, second part was about awareness regarding use of EC. Information about EC included its knowledge, details of administration, availability and side effects. Basic awareness about contraceptive methods was also assessed. Various perceptions like fear and myths were noted. This reflected the attitude of married women in Haryana toward the use of emergency contraceptive which was studied. Knowledge regarding EC effect on sexual behaviour and fertility in general was also evaluated. After the questionnaire, opportunistic counselling was done and people were encouraged to ask queries and encouraged to get further awareness from the investigating team. Information on benefits of EC methods, correct usage, timing, clearing doubts regarding EC methods, and queries regarding regular contraception were also discussed.

An informed consent was taken from all the participants and the study was approved by the institutional ethical committee.

\section{Statistical analysis}

The data were collected, analysed, and compared with data available in literature. For analysis, the variables were summarized using descriptive summary measures, expressed as mean $( \pm S D)$ for continuous variables, and percentage for categorical variables.

\section{RESULTS}

A total of 500 women were enrolled in the study.

Table 1: Socio-demographic details of participants.

\begin{tabular}{|c|c|c|}
\hline Variables & Frequency & Percentage (\%) \\
\hline \multicolumn{3}{|l|}{ Age } \\
\hline $18-23$ & 183 & 36.6 \\
\hline $24-29$ & 256 & 51.2 \\
\hline$\geq 30$ & 61 & 12.2 \\
\hline \multicolumn{3}{|l|}{ Place } \\
\hline Urban & 280 & 56 \\
\hline Rural & 220 & 44 \\
\hline \multicolumn{3}{|c|}{ Age at marriage } \\
\hline$<18$ & 137 & 27.4 \\
\hline$\geq 18$ years & 363 & 72.6 \\
\hline \multicolumn{3}{|c|}{ Socioeconomic status } \\
\hline Middle & 25 & 5 \\
\hline Lower middle & 123 & 24.6 \\
\hline Lower & 352 & 70.4 \\
\hline \multicolumn{3}{|l|}{ Religion } \\
\hline Hindu & 418 & 83.6 \\
\hline Muslim & 42 & 8.4 \\
\hline Others & 40 & 8 \\
\hline \multicolumn{3}{|c|}{ Education of women } \\
\hline Literate & 415 & 83 \\
\hline Illiterate & 85 & 17 \\
\hline \multicolumn{3}{|l|}{ Parity } \\
\hline Primiparous & 77 & 15.4 \\
\hline Multiparous & 423 & 84.6 \\
\hline \multicolumn{3}{|c|}{ Occupation of women } \\
\hline Homemaker & 379 & 75.8 \\
\hline Labourer & 7 & 1.4 \\
\hline Service & 108 & 21.6 \\
\hline Other & 6 & 1.2 \\
\hline \multicolumn{3}{|l|}{ Type of family } \\
\hline Nuclear & 184 & 36.8 \\
\hline Joint & 316 & 63.2 \\
\hline
\end{tabular}

Table 1 summarizes the sociodemographic details of the women who participated in the study. Of the total population under study, $415(83 \%)$ were literate and 85 (17\%) were illiterate. Women from rural background were $56 \%$ and $44 \%$ belonged to urban background. Women belonging to Hindu religion were $83 \%, 8.4 \%$ were Muslims and rest were other religions. Majority of women were homemakers $(75 \%)$ and $63.2 \%$ were from joint family. Regarding knowledge, awareness, attitude and usage of EC, more than $50 \%$ had never heard about EC. Further questions about knowledge and experience of women around emergency contraception were asked from participants who were aware of EC and depth of their knowledge was assessed. Details are summarized in Table 2. 
Table 2: Women's awareness of EC, knowledge levels and factors affecting EC use and use among currently married women in Haryana.

\begin{tabular}{|c|c|c|}
\hline Characteristics & Frequency & Percentage (\%) \\
\hline \multicolumn{3}{|c|}{ Ever heard about emergency contraception $(n=500)$} \\
\hline Yes & 240 & 48 \\
\hline No & 260 & 52 \\
\hline \multicolumn{3}{|c|}{ Used EC before $(n=240)$} \\
\hline Yes & 128 & 53.3 \\
\hline No & 112 & 46.6 \\
\hline \multicolumn{3}{|c|}{ Source of information $(n=240)$} \\
\hline Television & 203 & 84.58 \\
\hline Radio & 2 & 0.83 \\
\hline Newspaper & 1 & 0.41 \\
\hline Husband & 20 & 8.3 \\
\hline Family & 10 & 4.1 \\
\hline Health worker & 5 & 2.0 \\
\hline \multicolumn{3}{|c|}{$\begin{array}{l}\text { Awareness of Emergency contraceptive methods } \\
\text { available }(n=240)\end{array}$} \\
\hline Pills & 230 & 95.83 \\
\hline IUD & 5 & 2.08 \\
\hline Other & 5 & 2.08 \\
\hline \multicolumn{3}{|c|}{$\begin{array}{l}\text { How to get Emergency contraceptive method } \\
(n=240)\end{array}$} \\
\hline Chemist & 195 & 81.2 \\
\hline Health worker & 18 & 7.5 \\
\hline Hospital & 22 & 9.2 \\
\hline Healthcentre & 5 & 2.1 \\
\hline \multicolumn{3}{|c|}{ When to take EC pill } \\
\hline Before UPSI & 4 & 1.7 \\
\hline Within 72 hours & 10 & 4.2 \\
\hline More than 72 hours & 1 & 0.4 \\
\hline Don't know & 225 & 93.7 \\
\hline \multicolumn{3}{|c|}{ Would you like to use again $(n=240)$} \\
\hline Yes & 198 & 82.5 \\
\hline No & 42 & 17.5 \\
\hline \multicolumn{3}{|c|}{ Aware of any menstrual irregularity } \\
\hline Yes & 40 & 16.7 \\
\hline Not aware & 200 & 83.3 \\
\hline \multicolumn{3}{|c|}{ Is it an abortifacient? } \\
\hline Yes & 150 & 62.5 \\
\hline No & 90 & 37.5 \\
\hline \multicolumn{3}{|c|}{ Can repeat again in the same cycle } \\
\hline Yes & 36 & 15 \\
\hline No & 204 & 85 \\
\hline
\end{tabular}

Of those who were aware of EC, majority (95.83\%) knew about emergency contraceptive pills only. IUD as EC was known to a very few women $(2.08 \%)$. Of those who were aware, 54\% had used emergency contraceptive pill. Television was the most common source of information in most of the women and others sources were family (mostly husband), friends and social media. The source of procurement of EC pills was from chemist shops $(83.3 \%)$, and from health worker and hospitals (15\%). Very few women $(4.2 \%)$, knew the correct time for taking the EC pills. On asking open ended questions on their views on EC, majority had the misconception that the pill worked as an abortifacient and were afraid that it also could cause side effects on their body resulting in decreased fertility. Some informed they had used local made alternative of a concoction of some herbs and spices (kadha) taken after unprotected intercourse to protect them from pregnancy. However, on counselling about use and benefits of EC, they were willing to use it if needed in future. Participants were encouraged to disseminate the information of EC given to them to other women and majority of them agreed to do so.

\section{DISCUSSION}

This study was conducted on a section of rural and urban population in Haryana which is deemed to be representative of population of this state. About half of females (48\%), had heard about EC in the current study. Only $25.6 \%$ (128/500) respondents had ever used an emergency contraception method in our study. In a study by Myer et al, overall awareness was found to be $30 \%$ in a cohort of women in South Africa. ${ }^{3}$ A very low level of awareness of about $16 \%$ was reported in Haryana (overall) in National Family Health Survey in 2005-06 (NFHS-3) which rose to $54.5 \%$ in $2015-16$ (NFHS-4 ). ${ }^{1,4}$ In a study by Kushwah et al (2007) in Madhya Pradesh similar results as ours were noted where about half of the rural females had knowledge about EC but those were mostly young girls..$^{5}$ Adhikari et al from Nepal showed a good level of knowledge of EC where about two- thirds of college students had heard about EC and Tripathi et al, from their survey among knowledge of EC among health care providers concluded that majority of health care providers did not have precise knowledge about the subject. ${ }^{6,7}$ Mehra et al, from Chandigarh (India) showed a poor level of awareness where only $1 \%$ of women seeking abortion knew about EC. ${ }^{8}$ Nigam et al showed only $2 \%$ of the married females from rural Uttar Pradesh were aware of EC. ${ }^{9}$ In a study from Ethiopia, only $6.8 \%$ of graduating female students had ever used the method. ${ }^{10}$ Takkar et al reported usage of EC by about $10.3 \%$ educated working women. ${ }^{11}$ Tafuri et al in Southern Italy reported EC use in $16 \%$ of women. ${ }^{12}$ These variations may be attributed to difference in terms of literacy status and occupation as most of the females in our study were homemakers and literacy rate was $83 \%$ in study population. Also, these studies for comparison are a decade older when EC was not so much known. The difference in percentages of knowledge about EC in different studies can also be attributed to the different sociodemographic and cultural patterns of the study populations. The level of awareness of EC has been increasing in India, both in rural and urban regions. The percentage of awareness of EC in $48 \%$ women in the current study, confirms that there is an increasing trend. The level of EC knowledge was however very poor in our study. Though around half women in our study had heard about EC but various methods available and timing of taking EC was not known. Only $4.1 \%$ women knew the 
correct time of taking EC pill in our study. Surprisingly, IUD as a method of EC was known to only $2 \%$ women. Television was the found to be the most common source of getting information of EC in around $85 \%$ of cases. The other sources of information in this study were husbands or other family members just contributing to around $12 \%$. Media $(69.3 \%)$ was also reported the main source of information of EC in a study conducted in Ethiopia by Ahmed at al. ${ }^{13}$ Television being a very popular public media does have impact on the mind set of people. If consistent messages regarding EC via television in local languages are conveyed, these definitely have the potential to bring about a change in the behaviour regarding use of EC among the rural population also. Nearly $81 \%$ of subjects who had heard of EC had obtained it from a chemist in our study. In a study from Nigeria, $54.4 \%$ participants obtained EC from patent medicine store and participants in this study were school students. ${ }^{14}$

Health workers, anganwadi workers and hospital contributed to only $18.5 \%$ as a source of getting EC. This does bring a serious thought that the people who are the main link for any implementation of government programmes are actually not contacted for correct advice.

In addition, most participants $(93.7 \%)$ in our study did not know about the appropriate interval for efficacy between unprotected sex and taking EC. Correct knowledge of timing of EC was demonstrated by $22 \%$ in a study by Pearson et al and $13.6 \%$ of population by George et al. ${ }^{15,16}$ Our study reaffirms the presence of poor knowledge about the correct timing of EC. In a study from Pakistan, better knowledge $(42.4 \%)$ about the correct time for taking EC after unprotected sex was observed. ${ }^{17}$ Our study revealed that the knowledge about EC was significantly higher among the literates. These findings are coherent to those reported by Mittal et al 2003 where the majority of acceptors were less than 30 years of age and were literate. ${ }^{18}$

Studies have also shown that EC does not increase the risky sexual practices or behaviours. ${ }^{19}$ Majority of women participating in study, after counselling did agree to use EC in future if needed. In this study, it was observed that although the awareness of presence of emergency contraceptive measures was rising, there was hesitancy in accepting the methods due to various myths and misconceptions. Also, the knowledge about correct use of EC was lacking in majority of the population under study and social taboos attached to the topic were a major hindrance for women to access knowledge from health care practitioners. Since, education is the mainstay and significant predictor of success of family planning methods, imparting knowledge about correct use of EC through television, social media and effective incorporation of knowledge of EC use in sex education programs for young people can greatly help to achieve the targets and to prevent unplanned pregnancies and unsafe abortions.

\section{CONCLUSION}

So, the findings of our study affirm a poor knowledge about EC use specially in the rural population of Haryana. In spite of introduction of EC in government supply for almost over a decade, its knowledge still remains poor. Awareness of EC has been spread well by the media and Government efforts, but an unmet need is still prevailing about the education of people of its correct use. It is imperative to formulate plans for disseminating its knowledge more through health workers and health facilities and try to educate the people about EC.

Funding: No funding sources

Conflict of interest: None declared

Ethical approval: The study was approved by the Institutional Ethics Committee

\section{REFERENCES}

1. Summary of key findings. India fact sheet, NFHS- 3, 2005-06. Available at: http://www.rchiips.org/nfhs/nfhs3.shtml.

2. Annual Health Survey (2010-11). Office of the Registrar General and Census Commissioner, India. Ministry of Home Affairs, Government of India. New Delhi: ORG; 2010:11.

3. Myer L, Mlobeli R, Cooper D, Smit J, Morroni C. Knowledge and use of emergency contraception among women in the Western Cape province of South Africa: a cross-sectional study. BMC Women's Health. 2007;7:14.

4. Summary of key findings. India fact sheet, NFHS- 4, 2015-16. Available at: http://rchiips.org/nfhs/NFHS4Reports/Haryana.pdf.

5. Kushwah SS, Mittal A. Perceptions and practice with regard to reproductive health among out of school adolescents. Indian J Community Med. 2007;32(2):141-3.

6. Adhikari R. Factors affecting awareness of emergency contraception among college students in Kathmandu, Nepal. BMC Women's Health. 2009;9:27.

7. Tripathi R, Rathore AM, Sachdev J. Emergency contraception: knowledge, attitude and practice among health care providers in North India. J Obstet Gynecol Res. 2003;29:142-6.

8. Mehra R, Goel P, Dua D, Huria A. Knowledge of emergency contraception among women coming for induced abortion. J Obstet Gynecol India. 2006;56(3):233-5.

9. Nigam A, Maheshwari N, Prakash A. Knowledge of emergency contraception and Contraceptive practices: Representative study from Rural Uttar Pradesh. Indian J Community Med. 2010;35(3):44950.

10. Tajure N, Pharm B. Knowledge, attitude and practice of emergency contraception among graduating female students of Jimma university, Southwest Ethiopia. Ethiop J Health Sci. 2010;20(2):91-7. 
11. Takkar N, Goel P, Saha PK, Dua D. Contraceptive practices and awareness of emergency contraception in educated working women. Indian $\mathrm{J}$ Med Sci. 2005;59:143-9.

12. Tafuri S, Martinelli D, Germinario C, Prato R. A survey of opinions on emergency contraception in young women in Southern Italy. Eur J Contracept Reprod Health Care. 2012;2(17):164-9.

13. Ahmed FA, Moussa K, Petterson KO, Asamoah BO. Assessing knowledge, attitude, and practice of emergency contraception: a cross- sectional study among Ethiopian undergraduate female students. BMC Public Health. 2012;12:110.

14. Nworah JAO, Sunday UM, Joseph OU, Monday OO, Josephat CA. Knowledge, attitude and practice of emergency contraception among students in tertiary schools in Anambra State Southeast Nigeria. Int Med Med Sci. 2010;2(1):1-4.

15. Pearson VA, Owen MR, Philips DR, Gray DJ, Marshall MN. Pregnant teenager's knowledge and use of emergency contraception. BMJ. 1995;310:1644.
16. George J, Turner J, Cooke E, Hennessey E, Savage W, Julian P, et al. Women's knowledge of emergency contraception. $\mathrm{Br} \mathrm{J}$ Gen Pract. 1994;44:451-4.

17. Irfan F, Karim SI, Hashmi S, Ali S, Ali SA. Knowledge of emergency contraception among women of childbearing age at a teaching hospital of Karachi. J Pak Med Assoc. 2009;59(4):236-40.

18. Mittal S, Anandalakshmy PN, Lakhtakiya M. Sociodemographic profile of emergency contraceptive users. J Family Welfare. 2003;45(2):14-7.

19. Mittal S. Emergency contraception: potential for women's health. Indian J Med Res. 2014:14.

Cite this article as: Kaur SP, Sharma S, Lata G. Knowledge and awareness of emergency contraception methods in rural and urban areas of Haryana. Int J Reprod Contracept Obstet Gynecol 2019;8:4793-7. 